\title{
Optimization of feeding rate and pressure of Orthodox Roller in Black Tea production
}

\author{
G. Abhiram*1, S. Jinthushayi ${ }^{1}$, N. S. Withanage ${ }^{1}$
}

1Department of Export Agriculture, Uva Wellassa University of Sri Lanka

\begin{abstract}
The objective of this study was to optimize the performance of orthodox roller (225 $\mathrm{kg})$ in black tea manufacturing by varying the pressure and feeding rate at Wewassa Tea Factory, Passara. Three levels of pressure (P1 - 10 min-no pressure, 10 min-touch bar, P2 - 10 min-no pressure, 5 min-1/4 pressure,5min-no pressure and P3 - $10 \mathrm{~min}$ - no pressure, $3 \mathrm{~min}-1 / 4$ pressure, $2 \mathrm{~min}$ - 1/2 pressure) and three levels of feeding rate to the roller $(200,205$ and $210 \mathrm{~kg})$ were used as treatment combinations. Currently, the factory using P1 pressure and $200 \mathrm{~kg}$ feeding rate for tea manufacturing. Particle size analysis, brightness, TF/TR and organoleptic properties were measured for the triplicate samples and compared with the sample prepared with the factory standard. The results revealed, there is a significant effect of pressure and feeding rate on particle size analysis, but there is no significant effect on color, ratio between theaflavins (TF), thearubigins (TR) and sensory analysis $(p<0.05)$ The treatment combination of feeding rate $210 \mathrm{~kg}$ and Pressure P2 has given high amount of particle size belongs to No 3 mesh size while conserving other chemical and organoleptic parameters, thus it can be concluded that this treatment combination is the best.
\end{abstract}

Keywords: Black tea manufacturing, Feeding rate, Orthodox roller, Particle size, Pressure.

\section{Introduction}

Sri Lanka is one of the largest tea producers in the world. Sri Lankan tea industry annually produces about 320 million $\mathrm{kg}$ of made tea and accounts for 9\% share of world tea production and about $19 \%$ of total global tea exports (Sanne van der Wal, 2008; Annual Performance Report 2013: Ministry of Plantation Industries). Out of the given production output, the country has manufactured approximately 95\% orthodox black tea annually which is basically intended for export representing $32 \%$ of the global demand for orthodox black tea (Annual Performance Report 2013: Ministry of Plantation Industries) where Sri Lanka is still the market leader for orthodox black tea (Janaka and Suwendrani, 2011).

The common black tea processing unit operations are withering, rolling, oxidation and drying. Withering is done to bring down the moisture from approximately 70$80 \%$ to $60-70 \%$ on a wet basis (Deb and Pou,
2016). Withered leaves are rolled to break the cell of tea leaf and the released leaf juice help to enhance the chemical changes. Oils are released with this rolling process that gives the tea its distinctive aroma. The rolling process has a vital role in desired character of the black tea (Ozdemir et al., 1992). Fermentation is the next step to rolling in which a series of complex chemical reactions taken place within the cell (Roberts, 2008). In fermentation process polyphenol oxidase (PPO) oxidizes the flavan-3-ols in the vacuoles and polymerized to form thearubigins (TRs) and theaflavins (TFs) (Bailey et al., 1993).

A well-designed rolling programme for use during orthodox manufacture is essential for achieving the following: an optimum fermentation time for each batch of dhool (or rolled particles) to ensure quality and prevent the dhool getting overfermented or under fermented, a continuous feeding of the drier with wet dhool for higher efficiency, a maximization 
of worker productivity, and efficient machinery usage (Dahanayaka et al., 2002).

Application of pressure is essential for squeezing out the sap and forming dhool. With an epicyclical pressure roller, it is applied laterally by the central fitting. In the batten-pressure cap technique, it is applied from the top by lowering the pressure cap (Kumar et al., 2013). The variations of pressure periods in different factories are simply bewildering - 5 minutes on 5 off, 7 on 3 off, 4 on 3 off, 8 on 2 off and even 2.5 on 2.5 off. There is no special reason for adhering to any particular combination. For economic reasons, the amount of leaf charged into a roller must be as high as possible, but for successful rolling one of the essential conditions for which is brisk circulation of the leaf under pressure, charges must not be excessively high (Kumar et al., 2013).

During tea processing, the degree of curling, crushing and pressing of the tea leaves varies according to the rolling method used and the characters of the green tea leaves. Hence, much of the developed characteristics of black tea strictly depend on the processing system (Takeo and Mahanta, 1983; Van Lelyveld and De Rooster, 1986).

These are spread out or staked on racks immediately for fermentation, while the remaining coarse leaves are rolled for a further 20 minutes under higher pressure. The rolling and roll breaking process is continued up to 3 rd dhool or 4th dhool and the rest of the coarse leaves which are not passed through the last sieves called the big bulk. As a matter of fact, short rolling time produces larger leaf grades, while longer rolling produce smaller leaf grades (Samaraweera and Mohamed, 2008).

Liquor colour, brightness, appearance, liquoring properties, strength and aroma are the properties determine the quality of black tea and these characters of tea are tested by the tea tasters in tea sensory analysis (Keegel, 1959; Sanderson, 1972; Hazarika et al., 2002). Tea tasting is the most common evaluation method to judge its price and quality. Chemical components, which are responsible for the quality of black tea, are oxidized polyphenols such as theaflavins (TF) and thearubigins (TR), caffeine, amino acids, carbohydrates etc. (Sanderson, 1965). During the rolling operation, polyphenol oxidase and polyphenols are mixed together and produce TF and TR, which directly affect the quality of made tea (Owuor et al., 1987).

At present "Wewassa Tea Factory" using 10 min-no pressure and 10 min-touch bar pressure (P1) and $200 \mathrm{~kg}$ feeding rate (F1) for $225 \mathrm{~kg}$ orthodox roller. The roller cannot be used with maximum capacity since it reduces the rolling level and the optimum pressure was not known to increase the feeding rate. The study was conducted to identify the effect of pressure and feeding rate on particle size analysis and tea liquor characteristic and to find the best combination of pressure and feeding rate for the optimum operation.

\section{Materials and Methods}

\subsection{Experimental Setup}

Orthodox roller with $225 \mathrm{~kg}$ jacket size was selected for this study. Maintenance of orthodox roller was done before each treatment to maintain the even condition throughout the study. The withered tea leaves with $60 \pm 1 \%$ withering level were selected for the rolling process. A preliminary study was conducted to select the optimum range of pressure and feeding rate for the orthodox roller. Based on the results of the preliminary study the experiment was conducted by changing 3 levels of Pressure and three levels of Roller Feeding Rate as shown in table 1. 
Table 1. Three levels of Feeding Rate variations and Pressure variations.

\begin{tabular}{ll}
\hline Feeding Rate & Applied Pressure \\
\hline F1 - 200 kg & P1 - 10 mins no pressure and 10 mins touch bar \\
F2 - 205 kg & P2 - 10 mins no pressure, 5 mins $1 / 4$ pressure and 5 mins no pressure \\
F3 - 210 kg & P3 - 10 mins no pressure, 3 mins $1 / 4$ pressure and 2 mins $1 / 2$ pressure \\
\hline
\end{tabular}

Altogether 9 treatments were conducted by varying 3 feeding rates and 3 pressure levels. Each treatment was repeated for three times. Rolling time was maintained for twenty minutes for all treatments.

\subsection{Particle Size Analysis}

Rolled tea leaves were sent to reciprocatory roll breaker to separate according to the particle size using different size meshes (No 3 mesh and No 2 mesh). Leaves sieved by no 3 mesh was named as M1, leaves sieved by No 2 measured was named as M2 and the remaining leaves on mesh No 2 was considered as course leaves and was named as M3. The weight of each particle group was measured using an electronic balance. Leaves sieved with No 3 mesh (M1) were considered as optimum particle size in roll breaking process and only these leaves were sent to the fermentation bed and drier. The dried dhool was collected and stored in polyethylene bags and kept in a cool and dry place. Other leaves, M2 and $\mathrm{M} 3$, were sent to re-rolling to reduce the particle size. The particle distribution was calculated using following equation and expressed as weight percentage.

Particle size distribution $=$

$$
\frac{\text { Weight of seived tea leaf }}{\text { Total leaf wight fed to roller }} \times 100 \%
$$

\subsection{Determination of Theaflavin (TF) and Thearubigin (TR) content in black tea}

A tea infusion was made by adding $375 \mathrm{~mL}$ boiling distilled water into a vacuum flask with $9 \mathrm{~g}$ of black tea sample and shaken for ten minutes in a mechanical shaker. The infusion was filtered through a cotton wool into a flat-bottomed flask and allowed to cool to room temperature. Extraction steps were repeated for all 27 samples.

Roberts and Smith method (1963) was used to determine Theaflavin and Thearubigin in black tea. Four $\mathrm{mL}$ portion of the ethyl acetate layer was taken and made up to 25 $\mathrm{mL}$ with methanol. $25 \mathrm{~mL}$ of the remaining initial ethyl acetate layer was partitioned with $25 \mathrm{~mL}$ of $2.5 \%$ aqueous sodium hydrogen carbonate and the aqueous layer is discarded. A $4 \mathrm{~mL}$ portion of the washed ethyl acetate layer was made up of $25 \mathrm{~mL}$ of methanol. Then $2 \mathrm{~mL}$ of saturated oxalic acid aqueous solution and $6 \mathrm{~mL}$ of water were added to a $2 \mathrm{~mL}$ portion of the aqueous layer left from the first extraction with ethyl acetate and diluted to $25 \mathrm{~mL}$ with methanol. Preparation of blank sample was done similarly as stated above without mixing the tea extract. The absorbance of the solutions was measured at $380 \mathrm{~nm}$ obtained using a UV-VIS spectrophotometer (Shimadzu, 2450). The spectrometric conversion factors, $\mathrm{F} 1$ equals to 0.36 and $F 2$ equals to 1.13 .

Theaflavin (TF) and Thearubigin (TR) content in tea infusion were calculated using the following equation respectively.

$$
\begin{aligned}
& T F \%=6.25 \times E C \times F 1 \\
& T R \%=\{12.5 E D+[6.25(E A-E C]\} \times F 2
\end{aligned}
$$

Where; EA, EB, EC and ED are optical densities of solutions A, B, C and D respectively. 


\subsection{Total colour measurement}

Two grams of tea leaves were dried in an oven at $103 \pm 20^{\circ} \mathrm{C}$ for 16 hours to constant weight. The percentage dry matter (DM\%) in the sample was then calculated when all the moisture has been removed. Dry matter was necessary since all the parameters are expressed on a dry weight basis.

The tea infusion of $1 \mathrm{ml}$ ( $9 \mathrm{~g}$ black tea in 375 $\mathrm{mL}$ boiling distilled water in a thermos flask) was mixed with $9 \mathrm{~mL}$ of distilled water and topped with methanol in a $25 \mathrm{~mL}$ volumetric flask. The optical density (E) was measured at $460 \mathrm{~nm}$. Distilled water was used as a blank. The total colour was calculated using the following equation.

Total Colour $\%=6.25 \times 4 E \times D M \%$

Where; DM\% is the dry matter percentage of tea leaves, $\mathrm{E}$ is the optical density of the tea infusion.

\subsection{Sensory Evaluation}

Sensory evaluation was done with the help of trained Tea Tasters who are employed in the Estern Brokers PLC. First, $2.5 \mathrm{~g}$ of tea sample was accurately measured using a balance and put into the brewing cup. Then about $150 \mathrm{~mL}$ boiled water $\left(100{ }^{\circ} \mathrm{C}\right)$ was poured into the brewing cup and kept for 5 minutes. After 5 minutes, brewed tea was poured into the tasting bowl. The infusion was placed on the lid of the brewing cup. No hint was given to panellists regarding the code assigned to the samples and each panellist was provided with a sensory evaluation sheet and asked to make an independent evaluation of the order. Liquor characteristics (colour, flavour and aroma), dry leaf characteristics (appearance, colour), infused leaf characteristics (colour) and overall acceptability of the samples and factory samples were evaluated under fivepoint hedonic scale.

\subsection{Statistical Analysis}

Two-factor factorial design was used for this study and data was analyzed using
Two-way Analysis of Variance technique (ANOVA) with 5\% significance level. Mean separation was done using a Dunnett Multiple Comparison test with 5\% significance level. Cluster analysis was used to group the similar kind of treatments based on particle size distribution. Friedman test was done for the sensory evaluation to select the best treatment. Minitab 16 was used for statistical analysis and Microsoft Excel 2010 was used for descriptive analysis.

The particle size of rolled tea leaf is a good indication of the degree of rolling and roller performance (Thevathasan and Kirtisinghe, 1974). The rolled leaves were sent through mesh No 2 and 3 and mesh No 3 (M1) gave small particles which could be selected for further processing. In some circumstances, when the massive bulk of withered tea was sent for rolling only sieved leaf with mesh No 2 (M2) also taken for further processing. Otherwise, both M2 and M3 dhool will be rejected for fermentation and will be sent to re-rolling to reduce the particle.

Batten type, mesh size of roll breaker, and application of pressures determine the dhool outturn of the orthodox roller (Keegel, 1959).The above figure shows the particle size analysis in weight percentage for different treatments. The treatment FR3P3 showed a high amount of small particle belongs to M1 group and significantly different from other treatments at 0.05 significance level. Next to that, FR3-P1 and FR3-P2 showed a higher amount of particles which belong to M3 group followed by FR2P1, FR2-P2 and FR2-P3. The least amount of M1 particle size was received during FR1$\mathrm{P} 2$ treatment. Therefore treatment FR3-P3 is selected as the best treatment in terms of particle size analysis. This treatment increased the particles belongs to M1 group by $6.67 \%$, which is $1 / 4$ times higher than the current production of the factory. 
3. Results and Discussion

Particle Size Distribution Analysis

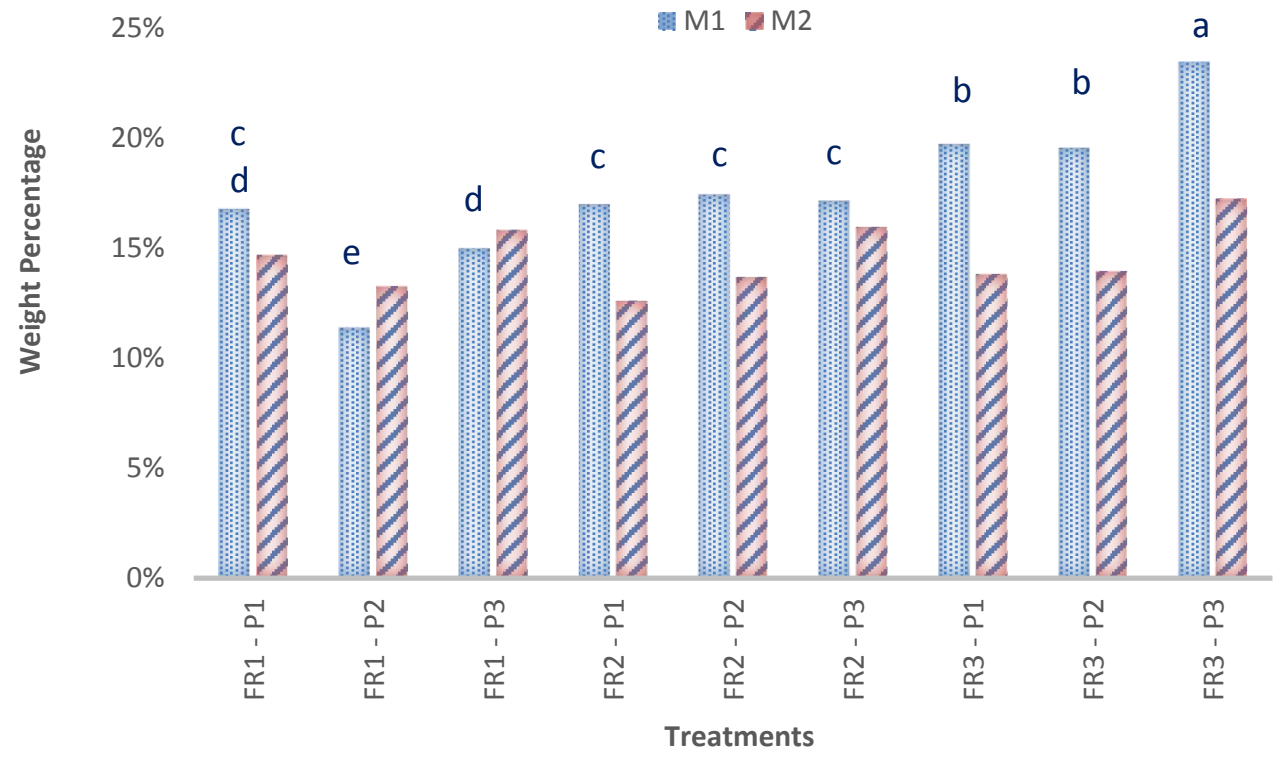

Fig. 1. Particle size analysis of rolled tea leaf for different treatments. The treatments carry different alphabetical letters showed significant difference at the $5 \%$ significance level.

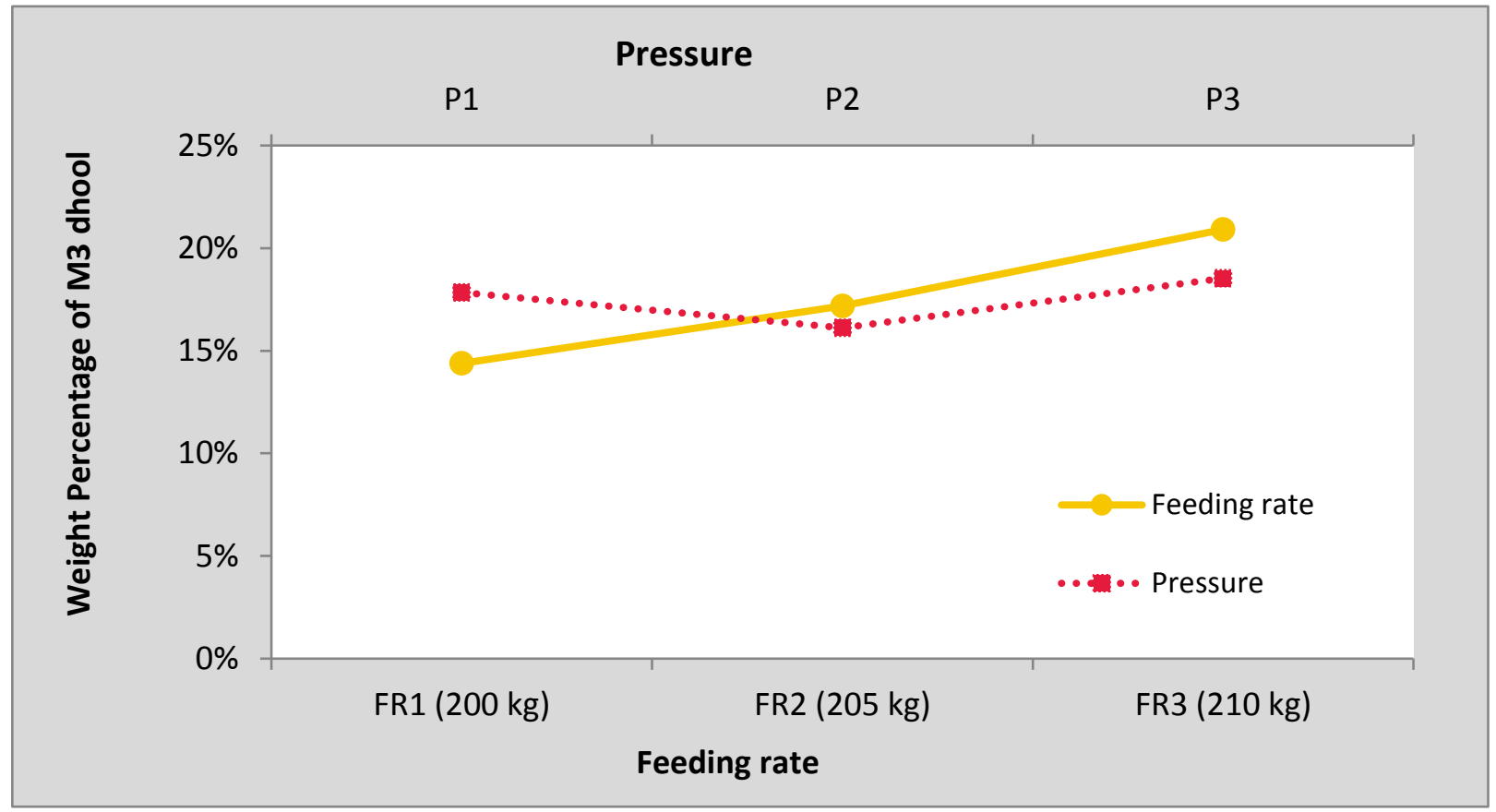

Fig. 2. The weight percentage of M3 dhool change with a feeding rate of orthodox roller and pressure applied to the tea leaf. 
The relationship of particle size with feeding rate and pressure is shown in figure 2. With the feeding rate, the particles become smaller (weight percentage belongs to $\mathrm{M} 3$ group increases). If the feeding rate is too small or pressure is higher than the required level of the orthodox roller, the tea leaves will be over macerated and become juicier. This will lead to loss of tea leaf sap and reduce the quality of the leaf. If orthodox rollers are overfed or pressure is not up to the sufficient level tea leaves will not be macerated properly and rollers release tea lumps (De Silva and Kirtisinghe, 1970). The observation clearly indicates that feeding rates 200, 205 and $210 \mathrm{~kg}$ did not overload the rollers and the applied pressure also was not under or over the required pressure.

\section{Theaflavins and thearubigins ratio (TF: TR) of infused tea}

Theaflavins and thearubigins ratio is a good indicator of the tea quality. The TF/TR ratio is another important factor in determining the quality of black tea. The TF/TR ratio should be $0.1-0.12$ to get balanced liquor and taste. Black teas containing higher ratios of theaflavins to thearubigins are always in higher demand in the auction market (Roberts and Smith 1963).

Table 2. Theaflavins and thearubiging ratio in infused tea samples

\begin{tabular}{cccc}
\hline & P1 & P2 & P3 \\
\hline FR1 & $0.065^{a}$ & $0.067^{a}$ & $0.070^{a}$ \\
FR2 & $0.070^{a}$ & $0.072^{a}$ & $0.074^{a}$ \\
FR3 & $0.078^{a}$ & $0.077^{a}$ & $0.070^{a}$ \\
\hline
\end{tabular}

The values carry different alphabetical letters showed significant difference at the $5 \%$ significance level.

There are no significant differences between the treatments at 0.05 significance level. These results showed that the rolling process did not affect the TF: TR ratio. Therefore during the rolling process, the pressure and feeding rate can be changed without affecting the TF: TR ratio. In all treatments the TF: TR ration was not in the range of $0.1-0.12$ and the possible reason was over fermentation of tea dhool. Robertson, 1992; Tufekci and Guner, 1997 have reported that TF/TR ratio varies with changes in fermentation times.

\section{Total colour percentage of infused tea}

Table 3. Total colour of infused tea samples

\begin{tabular}{cccc}
\hline & P1 & P2 & P3 \\
\hline FR1 & $15.25 \%{ }^{\mathrm{a}}$ & $15.01 \%{ }^{\mathrm{a}}$ & $14.78 \%{ }^{\mathrm{a}}$ \\
FR2 & $13.93 \%{ }^{\mathrm{a}}$ & $14.33 \%{ }^{\mathrm{a}}$ & $14.45 \%{ }^{\mathrm{a}}$ \\
FR3 & $15.45 \%{ }^{\mathrm{a}}$ & $15.15 \%{ }^{\mathrm{a}}$ & $15.12 \%{ }^{\mathrm{a}}$ \\
\hline The values carry & different & alphabetical \\
letters showed significant difference at 5\% \\
significance level.
\end{tabular}

The biochemical parameters, liquor colour and brightness were also considered as quality parameters by early researchers (Keegel, 1959; Kirthisinghe et al., 1968) for evaluating made tea quality. Liquor colour can be measured these days using atomic absorbance. There are no significant differences at $5 \%$ significance level for a total colour percentage between the treatments. This shows that the total colour will not change with the rolling process and not be affected by pressure variation and feeding rate.

Usually, the value of the total colour of Ceylon orthodox black teas was $4.17 \%$ (Steinhaus and Engelhardt, 1989). But these data showed higher values than this and this reflects that the tea was possibly over fermented. Fermentation temperature and duration determine the total colour of infused tea and total colour will increase with increasing fermentation temperature and time (Robertson 1992; Tufekci and Guner 1997). 


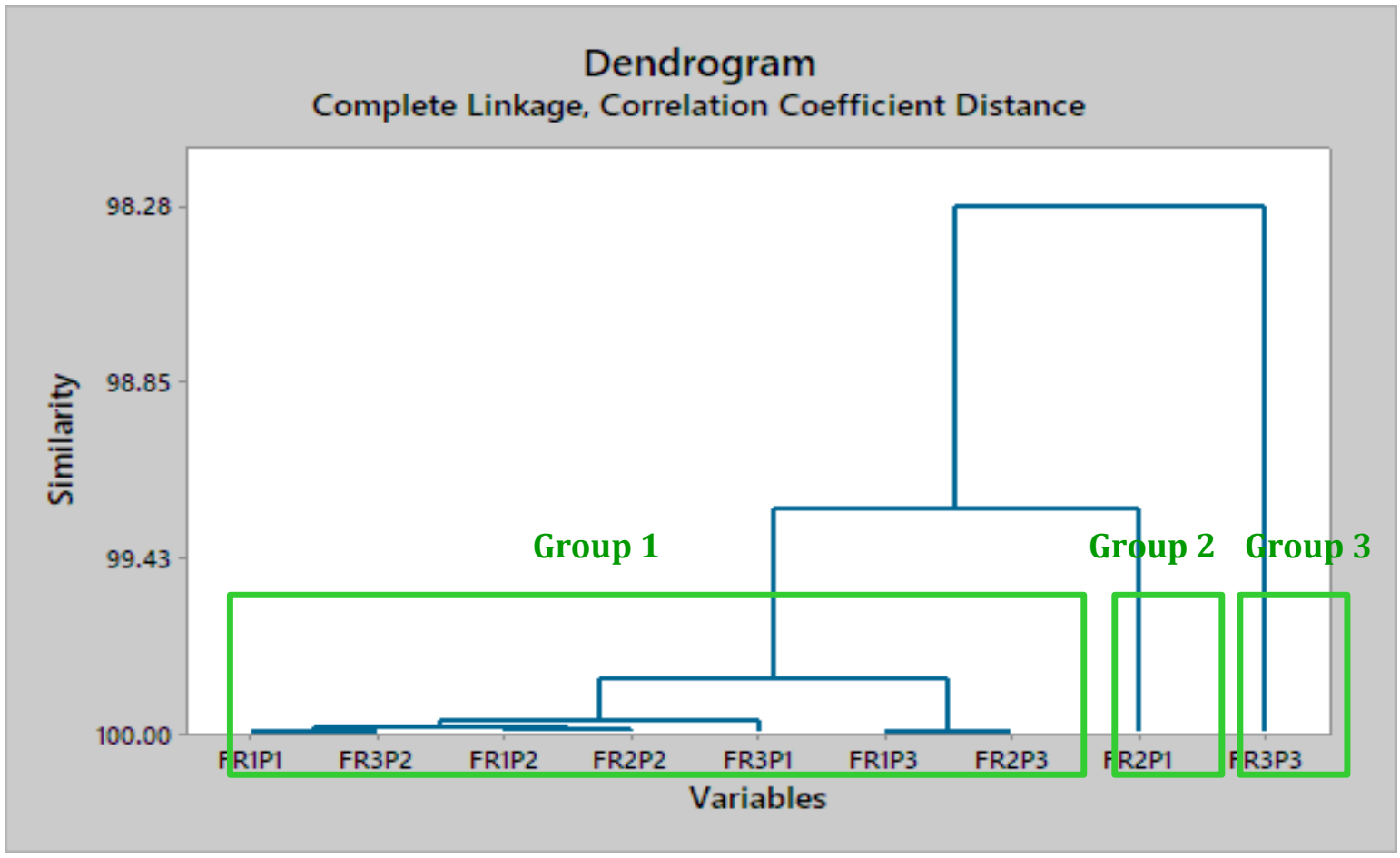

Fig. 3. Cluster diagram of the treatments.

\section{Selection of best group of treatments using cluster analysis}

Cluster analysis was used to remove certain treatment before the Friedman test to make it easy and avoid complications.

The treatments were grouped using particle size (M1) as the base. TF: TR ratio and total colour measurement were not considered since there was no significance between the treatments. According to the results of the cluster analysis, three groups were identified based on $99 \%$ similarity level. Seven treatments (FR1-P1, FR1-P2, FR1-P3, FR2-P2, FR2-P3, FR3-P1 and FR3P2) belong to Group 1 were selected as the best treatments since their particle sizes were small (weight percentage of M1 dhool was high). Other two treatments, FR2-P1 and FR3-P3, belong to Group 2 and Group 3 respectively were rejected based on $99 \%$ similarity. Selected seven treatments were undergone for Friedman test.

\section{Sensory Evaluation}

Liquor colour, liquor flavour, liquor aroma, infused tea leaf, dry leaf appearance, dry leaf colour and overall acceptability were the attribute used in the sensory evaluation. Friedman test for the sensory parameters was carried out for the selected seven treatments and plotted in the spider-web diagram. Those selected seven samples were named as S1 (FR1-P1), S2 (FR1-P2), S3 (FR1-P3), S5 (FR2-P2), S6 (FR2-P3), S7 (FR3-P1), S8 (FR3-P2) for the easiness of reference.

The demand for the tea depends on the liquor characteristics and dhool appearances. The results showed that both average liquor characteristics and dry leaf characteristics are superior in sample S8 (FR3-P2) and inferior in sample S6 (FR2P3). Sample S8 showed better results compared to other samples in all attributes other than liquor colour. In liquor colour only samples S6 and S7 showed better results than S8. Therefore the best sample was S8 and the best treatment was FR2-P3. 


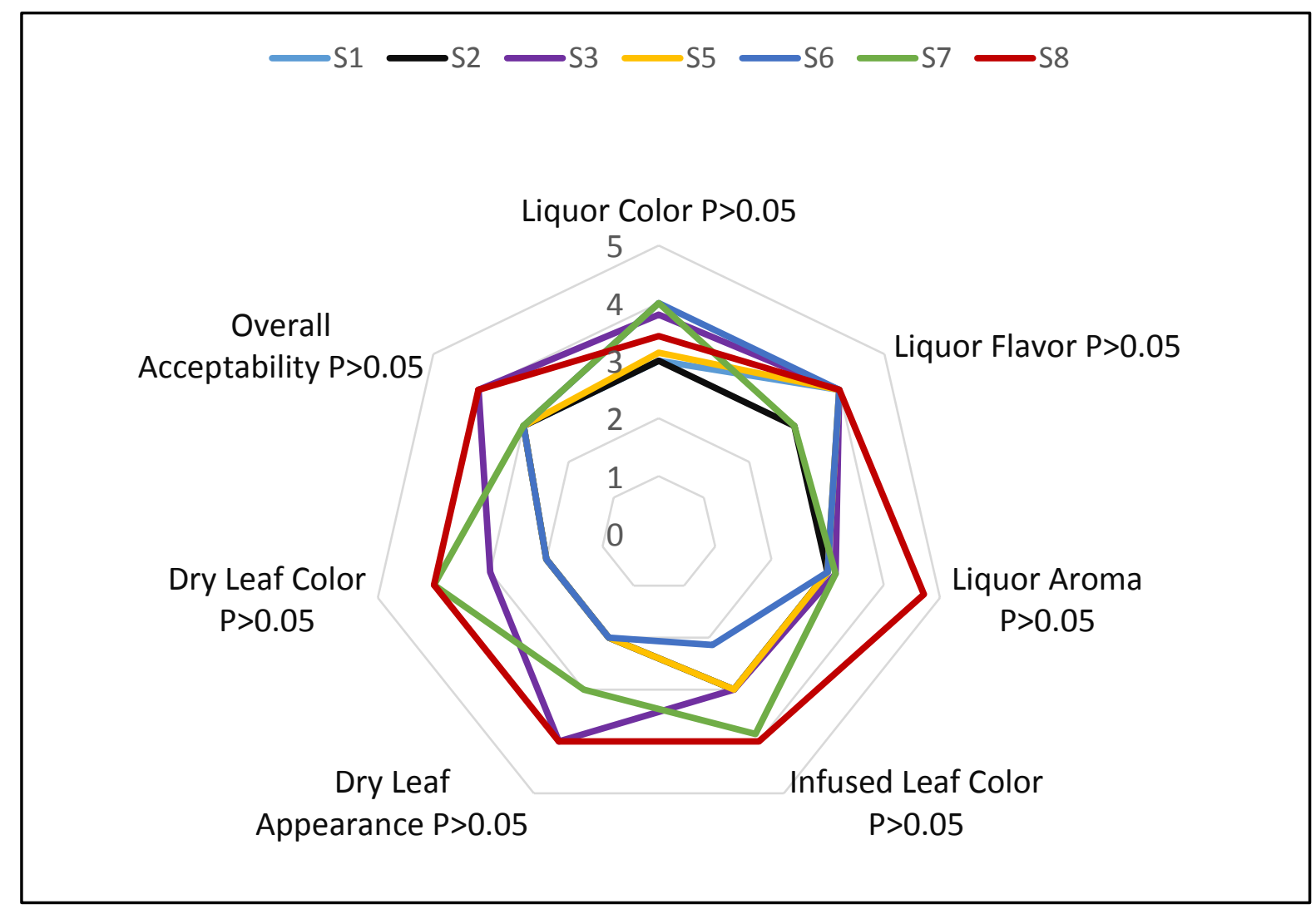

Fig. 4. Spider-web diagram for sensory analysis.

\section{Cost Beneficial Analysis}

Currently, Wewassa Tea Factory is applying P1 pressure and $200 \mathrm{~kg}$ feeding rate (FR1-P1 treatment) for the black tea manufacturing for the selected $225 \mathrm{~kg}$ jacket size orthodox roller. The results of this study suggested adopting $\mathrm{P} 3$ pressure and $210 \mathrm{~kg}$ of feeding rate (FR3-P3 treatment).

By adopting this FR3-P3 treatment the green tea leaf maceration can be increased by $10 \mathrm{~kg}$ per one cycle of orthodox rolling. This treatment has increased $17 \mathrm{~kg}$ of tea dhool belong to M1 group particle size and thus decreased the tea dhool sent to rerolling process.

Average fresh green tea intake is $12000 \mathrm{~kg}$ / day. The total rolling cycle at present was 60 and if the suggested treatment is adapted, the rolling cycles could be 57 . Therefore 3 cycles would be reduced per day with the suggested treatment. The average time for one rolling cycle is 20 minutes. The total time saving with the suggested treatment could be 60 minutes per day. Therefore, the total time saving for a month could be 30 hours.

\section{Conclusions}

Based on particle size only, treatment FR3P3 showed better results. When considering particle size and sensory evaluation FR2-P3 was the best treatment out of nine treatments. The feeding rate of orthodox roller and applied pressure had not influenced the TF: TR ratio and total colour of tea liquor. The rolling operation time could be reduced by 30 hours per months if the suggested FR3-P3 is adopted.

\section{References}

Annual Performance Report 2013: Ministry of Plantation Industries. 
Bailey, R.G., Nursten, H.E. and McDowell, I. (1993). The chemical oxidation of catechins and other phenolics: a study of the formation of black tea pigments. Journal of the Science of Food and Agriculture, 63(4): 455-464.

Dahanayaka, D. L. D. H., Jayasinghe, L. and Ziyad Mohamed, M.T. (2002). A Simple Computer Model for Selecting a Suitable Rolling Programme in Black Tea Processing-Sri Lanka Journal of Tea Science. 67(1/2): 32-36.

De Silva, W. C. A. and Kirtisinghe, D. (1970). The influence of feeding rates and rotor shaft speed on residence times of leaf within Rotorvanes. Tea Quarterly. 41: 127140.

Deb, S. and Pou, K. R. J. (2016). A Review of Withering in the Processing of Black Tea. Journal of Biosystems Engineering, 41(4):365372.

Hazarika, M., Goswami, M.R., Tamuly, P., Sabhapondit, S., Baruah, S. and Gogoi, M.N. (2002). Quality Management of TeaBiochemist's view. Two Bud, 49: 3-8.

Janaka, W. and Suwendrani, J. (2011). Implications of agri-food standards for Sri Lanka: Case studies of tea and fisheries export industries, Asia-Pacific Research and Training Network on Trade Working Paper Series, 104: 03 - 39.

Keegel, E.L. (1959). Tea made from clones. Tea Quarterly. 30: 134-141.

Kirthisinghe, D., De Silva, W.A.C. and Samarasingham, S. (1968). Manufacturing properties of Ceylon tea clones. Tea Quarterly, 39: 29-36.

Kumar, R.S.S., Murugesan, S., Kottur, G. and Gyamfi, D. (2013). Black tea: The plants, processing/manufacturing and production. In Tea in health and disease prevention. 5: 41-57.

Owuor, P.O., Obanda, M.A., Othieno, C.O., Horita, H., Tsushida, T. and Murai, T.
(1987). Changes in the chemical composition and quality of black tea due to plucking standards. Agricultural and Biological Chemistry, 51(12): 3383-3384.

Ozdemir, F., Gokalp, H. Y. and Nas, S. (1992). Effect of rolling method on physical characteristics of rolled tea leaves. Sri Lanka Journal of Tea Science. 61(2): 51-58.

Roberts, E.A.H. and Smith, R.F. (1963). Phenolic substances of manufactured tea.11. Spectrophotometric evaluation of tea liquors. Journal of the Science of Food and Agriculture. 14: 689-700.

Roberts, G.R. (2008). Principles of tea manufacture. Hand Book on Tea. (Ed.) A. K. N. Zoysa. Pp 261-264. Tea Research Institute of Sri Lanaka, Talawakelle, Sri Lanka.

Robertson, A. (1992). The chemistry and biochemistry of black tea production-the non-volatiles. In Tea: Cultivation to Consumption, ed. K. C. Willson and M. N. Clifford. Chapman and Hall, London, UK, pp. 555-601.

Samaraweera D. S. A., (2008) Chapter 20. Technology of Tea Processing: Hand Book on Tea, Revised by Samaraweera D. S. A. and Mohammed, M. T. Z., pp. 265 - 322. Tea Research Institute Sri Lanka, 15 edition.

Sanderson, G.W. (1965). On the chemical basis of quality in black tea. Tea Quarterly. 36(4), 172-182.

Sanderson, G.W. (1972). The chemistry of tea and tea manufacturing. Structural and functional aspects of phytochemistry. Academic Press, London pp.247-316.

Sanne van der Wal (2008). Sustainability issues in the tea sector: A comparative analysis of six leading producing countries, Centre for Research on Multinational Corporations. Pp 95. Amsterdam, Netherlands. 
Steinhaus, B. and Engelhardt, U.H. (1989). Theaflavins in black tea Comparison of the flavognost and HPLC analysis-preliminary in results Theaflavins in black tea. Comparison of the flavognost and an HPLC method. Vorläuflge Ergehnisse. Journal of Food Examination and Research, 188 (6): 509-511.

Takeo, T. and Mahanta, P. K. (1983). Comparison of black tea aromas of orthodox and CTC tea and of black teas made from different varieties. Journal of the Science of Food and Agriculture, 34: 307-310.
Thevathasan, A. and Kirtisinghe, D. (1974). The influence of withers and the rolling process on dhool and grade outturns and made tea characteristics. Tea Quarterly, 44 $(2,3): 122-127$.

Tüfekci, M. and Güner, S. (1997). The determination of optimum fermentation time in Turkish black tea manufacture. Food chemistry, 60(1): 53-56.

Van Lelyveld, L. V. and De Rooster, K. (1986). Effect of field practice and factory processes on black tea quality. The Journal of Horticultural Science and Biotechnology. 61: 549-553. 